\title{
Peningkatan Peran Keluarga Dalam Pendampingan Trias Penatalaksanaan Penderita Diabetes Melitus Pada Lansia Di Kelurahan Cipayung Jakarta Timur
}

\author{
Yenni Ariestanti, Yeny Sulistyowati, Titik Widayati,Ign. Erik Sapta Yanuar, Hendra, Srikandi \\ Wibowoweni
}

Universitas Respati Indonesia

Email : yariestanti@yahoo.com

\begin{abstract}
Abstrak
Diabetes mellitus merupakan penyakit yang dapat menyebabkan penyakit lain (komplikasi). Pemeriksaan laboratorium bagi penderita DM diperlukan untuk menegakkan diagnosis serta memonitor terapi dan timbulnya komplikasi. Dengan demikian, perkembangan penyakit bisa dimonitor dan dapat mencegah komplikasi. Apabila kadar insulin sangat menurun, pasien mengalami hiperglikemia dan glukosuria berat, penurunan lipogenesis, peningkatan lipolysis dan peningkatan oksidasi asam lemak bebas disertai pembentukan benda keton (asetoasetat, hidroksibutirat dan aseton). Peningkatan keton dalam plasma mengakibatkan ketosis. Penderita dapat mengalami hipotensi dan syok. Akhirnya, akibat penurunan penggunaan oksigen otak, pasien akan mengalami koma dan meninggal. Hal demikian sering terjadi pada Lansia.

Upaya kesehatan usia lanjut adalah upaya kesehatan paripurna dasar dan menyeluruh dibidang kesehatan usia lanjut meliputi peningkatan kesehatan, pencegahan, pengobatan dan pemulihan. Dengan tujuan meningkatkan derajat kesehatan dan mutu kehidupan untuk mencapai masa tua yang bahagia dan berdaya guna dalam kehidupan keluarga dan masyakat sesuai dengan keberadaannya dalam masyarakat. Program yang digalakkan untuk Usila karena terkait dengan penyakit yang banyak di derita adalah Prolanis (Program Pengelolaan Penyakit Kronis). Tujuan Prolanis adalah mendorong peserta penyandang penyakit kronis mencapai kualitas hidupnya terutama kesehatan dan mencegah terjadinya komplikasi penyakit yang akan menjadi beban masalah untuk dirinya, keluarga dan masyarakat. Kader Prolanis menjadi ujung tombak pada pelayanan kesehatan terkait penyakit kronis pada Usila. Dalam mencapai tujuannya ada enam kegiatan pokok pada Prolanis yaitu: Konsultasi Medis, Edukasi Kelompok, Reminder melalui SMS Gateway, Home Visit, Aktivitas Klub dan Pemantauan Status Kesehatan. Mencermati permasalahan tersebut di atas, sangatlah penting dan mendesak untuk melakukan berbagai upaya perbaikan penaanganan DM pada Lansia. Hal ini dimaksudkan agar semua pihak yang terlibat memiliki pemahaman yang benar terkait manfaat dan dampak Trias Penanganan DM tersebut, yaitu Obat, Makanan dan Olahraga untuk mewujudkan Lansia yang tetap sehat, mampu berkarya dan produktifitas.

Pada tahun 2020 bulan Maret terjadi Pandemi Covid 19 sehingga pelaksanaan kegiatan Pengabdian Masyarakat tidak boleh mengadakan kegiatan Massa atau partia besar sehingga pelaksanaan PKM ini dilaksanakan secara Webinar Series, Adapun pelaksanaan Webinar series 1 tidak merubah tema hanya pelaksanaan yang bersifat online dengan mengundang

pihak pakar dengan melibatkan Kepala Puskesmas Dr. Apriyani dengan tema "Penyakit Diabetes Melitus di Masyarakat", pemaparan penelitian terkait penelitian oleh Dr. Yeny Sulistyowati, Msi.Med " Faktor genetik menjadi Faktor Dominan Resiko DM di Wilayah Kerja Puskesmas Cipayung dan pemeran tentang Peningkatan Peran Keluarga Dalam Upaya Pendampingan Penderita DM oleh Yenni Ariestanti, S.Si.T.,M.Kes
\end{abstract}

http://ejournal.urindo.ac.id/index.php/PAMAS

Article History :

Submitted 15 April 2021, Accepted 27 April 2021, Published 30 April 2021 
Dosen, Mahasiswa, Masyarakat umum dari seluruh Indonesia menjadi sasaran Webinar Serie tombak pemberian informasi dan pengetahuan yang benar kepada masyarakat, terutama Keluarga Penderita DM. Selanjutnya adalah keluarga itu sendiri karena diharapkan dengan pengetahuan yang baik maka sikap yang tadi nya negative menjadi positif sehingga perilaku penanganan DM menjadi benar. Keluarga penting untuk dilibatkan agar semua unsur yang terdekat dan sering berinteraksi dengan Lansia mempercepat terjadinya perubahan perilaku dalam menangani DM, sehingga penyakit yang diderita bisa dikendalikan, tidak mudah sakit, tetap sehat, produktif, mandiri di usia Lansia.

Adapun manfaat yang dapat dipetik dari kegiatan ini adalah: peserta memiliki wawasan, pemahaman, sikap dan perilaku sehat untuk diri dan lingkungannya, Lansia lebih mandiri dan meningkat produktifitasnya. Universitas sebagai institusi ilmiah akan memperoleh umpan balik pengembangan keilmuan, khususnya ilmu kesehatan di samping itu juga mendapatkan mitra dalam pembangunan masyarakat; dinas yang terkait dalam program ini adalah dinas kesehatan dan pendidikan terbantu dalam upaya peningkatan kesehatan masyarakat dan pengembangan kemampuan sumber daya manusia.

Kata kunci : Penyakit DM di Masyarakat, peran Keluarga DM, Faktor Genetik, Puskesmas Kecamatan Cipayung

\begin{abstract}
Diabetes mellitus is a disease that can cause other diseases (complications). Laboratory tests for DM sufferers are needed to establish a diagnosis and monitor therapy and complications. Thus, disease progression can be monitored and can prevent complications. When insulin levels are severely decreased, the patient experiences severe hyperglycemia and glucosuria, decreased lipogenesis, increased lipolysis and increased free fatty acid oxidation accompanied by the formation of ketones (acetoacetate, hydroxybutyrate and acetone). The increase in ketones in plasma results in ketosis. Sufferers can experience hypotension and shock. Finally, due to decreased brain oxygen use, the patient will fall into a coma and die. This often happens to the elderly.

Elderly health efforts are basic and comprehensive plenary health efforts in the field of elderly health including health improvement, prevention, treatment and recovery. With the aim of increasing the degree of health and quality of life to achieve a happy and efficient old age in family and community life in accordance with their existence in society. The program that was promoted for Usila because it was related to the many diseases he suffered was Prolanis (Chronic Disease Management Program). The aim of Prolanis is to encourage participants with chronic diseases to achieve a quality of life, especially health and to prevent complications from diseases that will become a burden for themselves, their families and society. Prolanis cadres are at the forefront of health services related to chronic disease in Usila. In achieving its goals there are six main activities at Prolanis, namely: Medical Consultation, Group Education, Reminder via SMS Gateway, Home Visit, Club Activities and Monitoring of Health Status.

Looking at the problems mentioned above, it is very important and urgent to make various efforts to improve the handling of DM in the elderly. This is intended so that all parties involved have a correct understanding of the benefits and impacts of the DM Handling Triassic, namely medicine, food and sports to create elderly people who remain healthy, able to work and be productive.
\end{abstract}


In March 2020, the Covid Pandemic 19 occurred so that the implementation of Community Service activities may not hold Mass activities or large parties so that the implementation of this PKM is carried out in a Webinar Series, the implementation of Webinar series 1 does not change the theme, only the implementation is online by inviting

the expert by involving the Head of the Puskesmas Dr. Apriyani with the theme "Diabetes Mellitus in the Community", the presentation of research related to research by Dr. Yeny Sulistyowati, Msi.Med "Genetic factors are the Dominant Risk Factors for DM in the Work Area of the Cipayung Community Health Center and the cast on Increasing the Role of Families in Supporting Patients with DM by Yenni Ariestanti, S.Si.T., M.Kes.

Lecturers, Students, The general public from all over Indonesia are the targets of the Serie A webinars to provide correct information and knowledge to the public, especially families with diabetes mellitus. Next is the family itself because it is hoped that with good knowledge, the attitude that was negative before becomes positive so that the DM handling behavior becomes correct. It is important for families to be involved so that all elements that are closest to and often interact with the elderly can accelerate behavior changes in handling DM, so that the disease they suffer can be controlled, do not get sick easily, remain healthy, productive, independent in the elderly.

The benefits that can be learned from this activity are: participants have insight, understanding, healthy attitudes and behavior for themselves and their environment, the elderly are more independent and their productivity increases. Universities as scientific institutions will receive feedback on scientific development, especially health sciences as well as get partners in community development; related agencies in this program are the health and education offices assisted in efforts to improve public health and develop human resource capacity.

Keywords: DM disease in the community, the role of the DM family, genetic factors, Cipayung District Health Center

\section{PENDAHULUAN}

Puskesmas adalah suatu organisasi kesehatan fungsional yang merupakan pusat pengembangan kesehatan masyarakat yang juga membina peran serta masyarakat disamping memberikan pelayanan secara menyeluruh dan terpadu di wilayah kerjanya dalam bentuk kegiatan pokok dan usaha kesehatan integrasi yang kegiatannya merupakan kegiatan lintas sektoral. Puskesmas mempunyai wewenang dan tanggung jawab atas pemeliharaan kesehatan masyarakat di wilayah kerjanya. Gedung layanan Puskesmas Cipayung.

Sarana kesehatan bersumber daya masyarakat juga sudah banyak yang dilakukan oleh pihak Puskesmas Cipayung, dalam rangka meningkatkan cakupan pelayanan kesehatan kepada masyarakat dilakukan dengan memanfaatkan potensi dan sumber daya yang ada di masyarakat, yaitu antara lain Posyandu balita, posyandu lansia dan Posbindu yang merupakan 
bentuk Upaya Kesehatan Bersumberdaya Masyarakat (UKBM). Pada tahun 2017 posyandu balita yang ada di wilayah puskesmas kecamatan cipayung sebanyak 128 . Jumlah posbindu sebanyak 35 posbindu. Jumlah posyandu lansia sekecamatan Cipayung sebanyak 51 Posyandu Lansia. Upaya kesehatan usia lanjut adalah upaya kesehatan paripurna dasar dan menyeluruh dibidang kesehatan usia lanjut yang meliputi peningkatan kesehatan, pencegahan, pengobatan dan pemulihan. Dengan tujuan meningkatakan derajat kesehatan dan mutu kehidupan untuk mencapai masa tua yang bahagia dan berdaya guna dalam kehidupan keluarga dan masyakat sesuai dengan keberadaannya dalam strata kemasyarakatan. Kegiatan yang dilakukan oleh puskesmas kecamatan Cipayung adalah memberikan pelayanan kesehatan secara langsung, kunjungan panti werdha, menggalakkan/ mengikutkan peran serta masyarakat melalui posyandu lansia. Di wilayah se-Kecamatan Cipayung selama tahun 2017 jumlah total usia lanjut sebanyak 36.264, sedangkan yang mendapatkan pelayanan kesehatan sebanyak 3.847 atau sebesar $10.61 \% .{ }^{1}$ Dalam pelaksanaan programnya Puskesmas juga di bantu oleh berbagai relawan dari tingkat Kecamatan sampai dengan RT, diantaranya ada Kader PKK, Posyandu baik Balita maupun Lansia, Jumantik, Jumantuk, serta Kader Prolanis. Program yang sedang digalakkan untuk Usila karena terkait dengan penyakit yang banyak di derita adalah Prolanis (Program Pengelolaan Penyakit Kronis). Tujuan Prolanis adalah mendorong peserta penyandang penyakit kronis mencapai kualitas hidupnya terutama kesehatan dan mencegah terjadinya komplikasi penyakit yang akan menjadi beban masalah untuk dirinya, keluarga dan masyarakat. Kader Prolanis menjadi ujung tombak pada pelayanan kesehatan terkait penyakit kronis pada Usila. Dalam mencapai tujuannya ada enam kegiatan pokok pada Prolanis yaitu: Konsultasi Medis, Edukasi Kelompok, Reminder melalui SMS Gateway, Home Visit, Aktivitas Klub dan Pemantauan Status Kesehatan. ${ }^{3}$ Berdasarkan data yang ada bahwa di Puskesmas Kediri ada sebanyak 51,5\% responden tidak patuh terhadap prolanis dan ada sejumlah $48,5 \%$ peserta yang patuh terhadap pelaksanaan program prolanis tersebut. Jika dikaitkan dengan usia Lansia maka data tersebut sangat berarti karena sangat rentan terjadinya angka kekambuhan penyakit bahkan memicu munculnya komplikasi berbagai penyakit lainnya.

\section{METODE}

1. Identifikasi sasaran, yaitu Dosen, Mahasiswa, Masyarakat umum dari seluruh Indonesia menjadi sasaran Webinar Series tombak pemberian informasi dan pengetahuan yang benar kepada masyarakat, terutama Keluarga Penderita DM. Dengan kegiatan ini maka 
data yang didapatkan akan lebih akurat mulai dari pelaksanaan program, evaluasi sampai dengan keberlanjutannya.

2. Konsultasi Medis, kegiatan ini berkaitan dengan peserta webinar yang ingin berkonsultasi mengenai keluhan yang dialami dengan dokter puskesmas Cipayung secara online tetnatng permasalahan yang dihadapi di keluarga dan masyarakat terkait DM.

3. Edukasi pihak pakar dengan melibatkan Kepala Puskesmas Dr. Apriyani dengan tema "Penyakit Diabetes Melitus di Masyarakat", pemaparan penelitian terkait penelitian oleh Dr. Yeny Sulistyowati, Msi.Med " Faktor genetik menjadi Faktor Dominan Resiko DM di Wilayah Kerja Puskesmas Cipayung dan pemeran tentang Peningkatan Peran Keluarga Dalam Upaya Pendampingan Penderita DM oleh Yenni Ariestanti, S.Si.T.,M.Kes.

\section{HASIL PELAKSANAAN PENGABDIAN}

Hasil pelaksananaan ini diharapkan agar Dosen, Mahasiswa, Masyarakat umum dari seluruh Indonesia menjadi sasaran Webinar Series tombak pemberian informasi dan pengetahuan yang benar kepada masyarakat, terutama Keluarga Penderita DM. Selanjutnya adalah keluarga itu sendiri karena diharapkan dengan pengetahuan yang baik maka sikap yang tadi nya negative menjadi positif sehingga perilaku penanganan DM menjadi benar. Keluarga penting untuk dilibatkan agar semua unsur yang terdekat dan sering berinteraksi dengan Lansia mempercepat terjadinya perubahan perilaku dalam menangani DM, sehingga penyakit yang diderita bisa dikendalikan, tidak mudah sakit, tetap sehat, produktif, mandiri di usia Lansia.

Adapun manfaat yang dapat dipetik dari kegiatan ini adalah: peserta memiliki wawasan, pemahaman, sikap dan perilaku sehat untuk diri dan lingkungannya, Lansia lebih mandiri dan meningkat produktifitasnya. Universitas sebagai institusi ilmiah akan memperoleh umpan balik pengembangan keilmuan, khususnya ilmu kesehatan di samping itu juga mendapatkan mitra dalam pembangunan masyarakat; dinas yang terkait dalam program ini adalah dinas kesehatan dan pendidikan terbantu dalam upaya peningkatan kesehatan masyarakat dan pengembangan kemampuan sumber daya manusia.

proses kegiatan yang dilakukan adalah :

1. Perijinan : Pengabdi dan Panitia mengadakan Perijinan dengan Pihak Puskesmas Cipayung dalam pelaksanaan kegiatan PKM . 
2. Panitia mengadakan Koordinasi dengan pihak terkait untuk pelaksanaan kegiatan Webinar Series 1 meliputi persuratan dengan pihak Puskesmas Kecamatan dan Rektor URINDO sebagai Pemberi sambutan, dan Pemateri dari pihak Puskesmas dan URINDO.

3. Pertemuaan Dilaksanakan pada hari Jumat, 16 Oktober 2020 adapun rincian data yang didapatkan dari hasil pengabdian adalah sebagai berikut :

a. Susunan Kegiatan Webinar :

Tabel 6.1.

Susunan Acara Kegiatan PKM melalui Webinar Series 1

Tema : Penyakit Tidak Menular

“Mengenal Lebih Dekat Diabetes Melitus (DM)

16 Oktober 2020

\begin{tabular}{|c|c|c|}
\hline No & Jam & Kegiatan \\
\hline 1 & $\begin{array}{l}08.45-09.00 \\
\text { WIB }\end{array}$ & Panitia Breafing \\
\hline 2 & $\begin{array}{l}09.00-09.05 \\
\text { WIB }\end{array}$ & Pembukaan MC \\
\hline 3 & $\begin{array}{l}09.05-09.10 \\
\text { WIB }\end{array}$ & Sambutan KPS \\
\hline 4 & $\begin{array}{l}09.10-09.15 \\
\text { WIB }\end{array}$ & Sambutan Rektor \\
\hline 5 & $\begin{array}{l}09.15-09.20 \\
\text { WIB }\end{array}$ & Sambutan Ka. Puskes \\
\hline 6 & $\begin{array}{l}09.20-09.25 \\
\text { WIB }\end{array}$ & Moderator Pembuka Diskusi Panel \\
\hline 7 & $\begin{array}{l}09.25-09.40 \\
\text { WIB }\end{array}$ & $\begin{array}{l}\text { Pemateri } 1 \text { (Dr. Apriyani) : "Penyakit Diabetes Melitus di } \\
\text { Masyarakat" }\end{array}$ \\
\hline 8 & $\begin{array}{l}09.40-10.05 \\
\text { WIB }\end{array}$ & $\begin{array}{l}\text { Pemateri } 2 \text { (Yenni Ariestanti, S.Si.T.,M.Kes) : “peningkatan } \\
\text { Peran Keluarga dalam upaya pendampingan penderita DM" }\end{array}$ \\
\hline 9 & $\begin{array}{l}10.05-10.35 \\
\text { WIB }\end{array}$ & Tanya Jawab/Diskusi \\
\hline 10 & $\begin{array}{l}10.35-10.50 \\
\text { WIB }\end{array}$ & Doorprice \\
\hline 11 & $\begin{array}{l}10.50-11.00 \\
\text { WIB }\end{array}$ & Penutup \\
\hline
\end{tabular}

b. Karakterisitik Responden

Peserta yang hadir dalam Kegiatan PKM dalam bentuk Webinar Seies 1 ini adalah dari Puskesmas, SMS. Poltekes, Uniska,Universitas Ilam Kalimantan, Unkris, MTSN, Universitas Surabaya, Unhan, Universitas Kalimantan, Klinik Islam, UNRIYO,UP 45, 
UP 45 Yogyakarta, Universitas Mataram dll(Terlampir) dengan latar belakang pekerjaan Dosen, Mahasiswa, Perawat, Bidan dan Umum.

c. Edukasi melalui pemeparan materi oleh pakar terkait DM di Masyarakat.

Kegiatan ini dalam bentuk pelatihan yang direncanakan melibatkan semua unsur dalam pelaksanaan program, diharapkan terjadi peningkatan pengetahuan, perbaikan sikap dan perilaku yang diikuti oleh jumlah peserta 158 Orang pelaksanaan kegiatan melalui Pemberian Materi Edukasi pada kegiatan PKM melalui Webinar LPPM Series 1 yang dengan diberikan dengan rincian sebagai berikut :

1. Pemateri 1 Dr. Apriyani dari Puskesmas Kecamatan Cipayung yang diberikan selama 15 Menit pada pukul 09.25-09.40 WIB dengan materi "Penyakit Diabetes Melitus di Masyarakat" dengan pembagian Definisi dan Gejala Diabetes Melitus, Prevalensi DM, 10 penyakit terbanyak di masyarakat Cipayung, Penegakkan Diagnosis DM, Klasifikasi DM, Faktor Resiko, masalah Pengendalian DM, Komplikasi DM, Target dan Capaian DM program PTM 2020 hingga TW2 Kec. Cipayung, Penatalaksanaan dan Pengendalian DM, Upaya Pengendalian Prevalensi Tinggi, Tantangan dan Rencana Tindak lanjut

2. Materi kedua oleh Yenni Ariestanti S.Si.T.,M.Kes yang diberikan selama 15 Menit yaitu 09.40-10.05 WIB dengan materi "Penyakit Diabetes Melitus di Masyarakat" tentang Pendahuluan, pengenalan keluarga terkait faktor resiko DM,Keluhan umum penderita DM, peran keluarga pendamping DM, Edukasi Keluarga DM, bantuan dari keluarga yang merawat klien $\mathrm{dm}$ di rumah sangat dibutuhkan, pemantauan Kadar Gula secara Mandiri ,perawatan keluarga DM dan pengelolaan dan perawatan Diabetes dalam Keluarga.

3. Diskusi online melaui Zoom dan Youtube yaitu :

a. Pertanyaan untuk dr. Apriyani

1) Bagaimana pengalaman puskesmas Cipayung dalam menangani Pasien Covid?

2) Penderita jenis DM apa yang terbanyak dan apa yang dilakukan untuk penderita di Kecamatan Cipayung

3) Apakah ada faktor yang paling mempengaruhi dalam naiknya angka kasus tersebut 
b. Pertanyaan untuk Yenni Ariestanti, S.Si.T.,M.Kes

Bagaimana cara pencegahan DM dari sisi Lifestyle yang dapat dilakukan ? mohon bagi ilmu dan pengalamnaya misal dari sisi pola makan apa saja yang harus dilakukan misal jumlah komsumsi, waktu mengkomsumsi atau mungkin cara pengolahan makannya

d. Evaluasi Pelaksanaan Seminar

Evaluasi pelaksanaan seminar dilaksanakan dengan mengunakan evaluasi melalui Google Form yaitu ada empat bentuk evaluasi peserta :

1. Proses registrasi dan informasi tata tertib pelaksanaan kegiatan.

Dari 158 peserta menyatakan bahwa proses registrasi dan Informasi tata tertib pelaksanaan kegiatan berjalan dengan Baik sebesar 142 orang (89 \%), Cukup 17 Orang (10\%) dan 1 orang (1\%).dengan gambar tabel sebagai berikut :

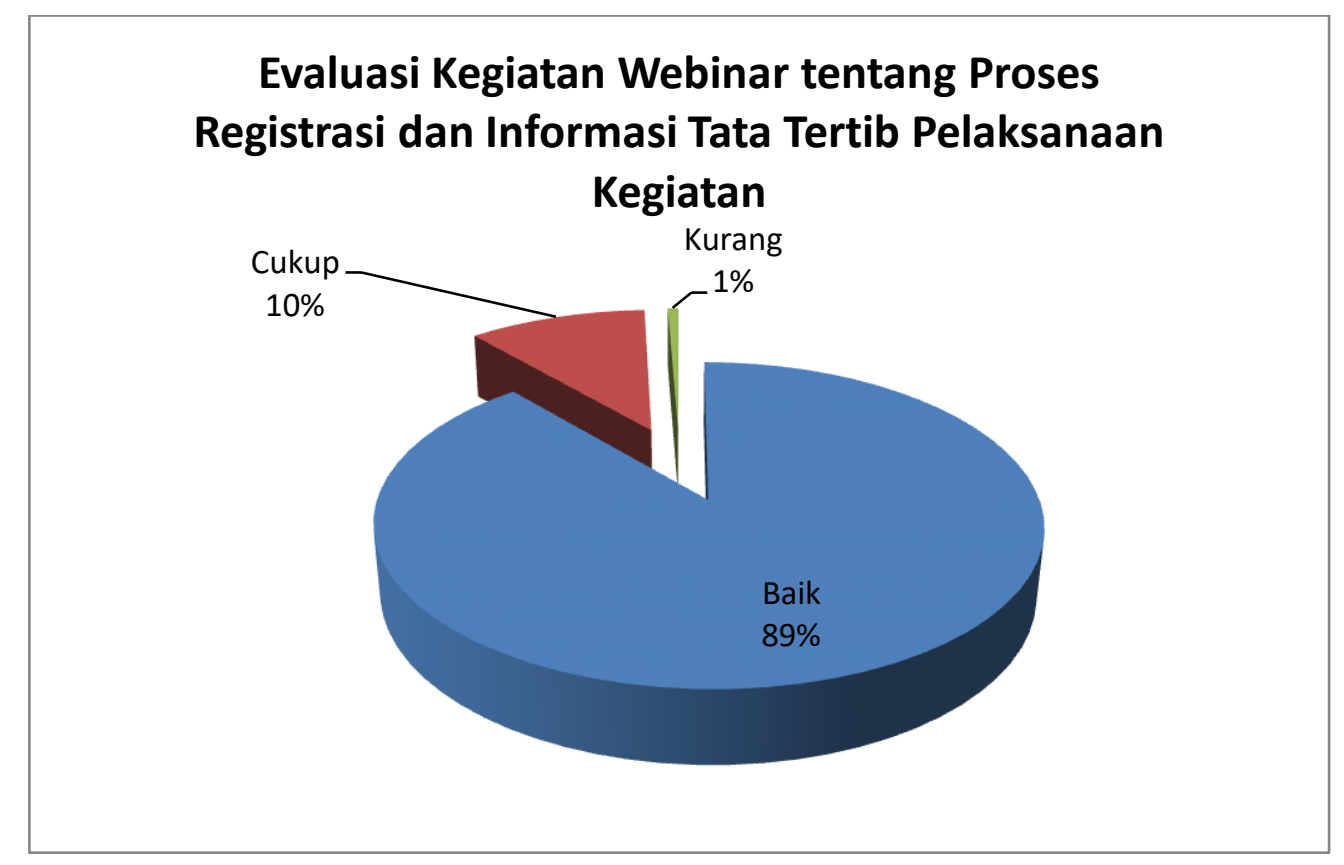

Gambar 6.1 . Hasil Evaluasi kegiatan webinar tentang proses Registrasi dan informasi tata tertib pelaksaaan kegiatan Webinar (sumber : google Form webinar series 1, 2020)

2. Materi yang disampaikan oleh narasumber Kemudahan dalam mengakses dan mengikuti kegiatan 
Dari 158 peserta menyatakan bahwa proses registrasi dan Informasi tata tertib pelaksanaan kegiatan berjalan dengan Baik sebesar 144 orang (91\%), Cukup 12 Orang (8\%) dan 2 orang (1\%).dengan gambar grafik sebagai berikut :

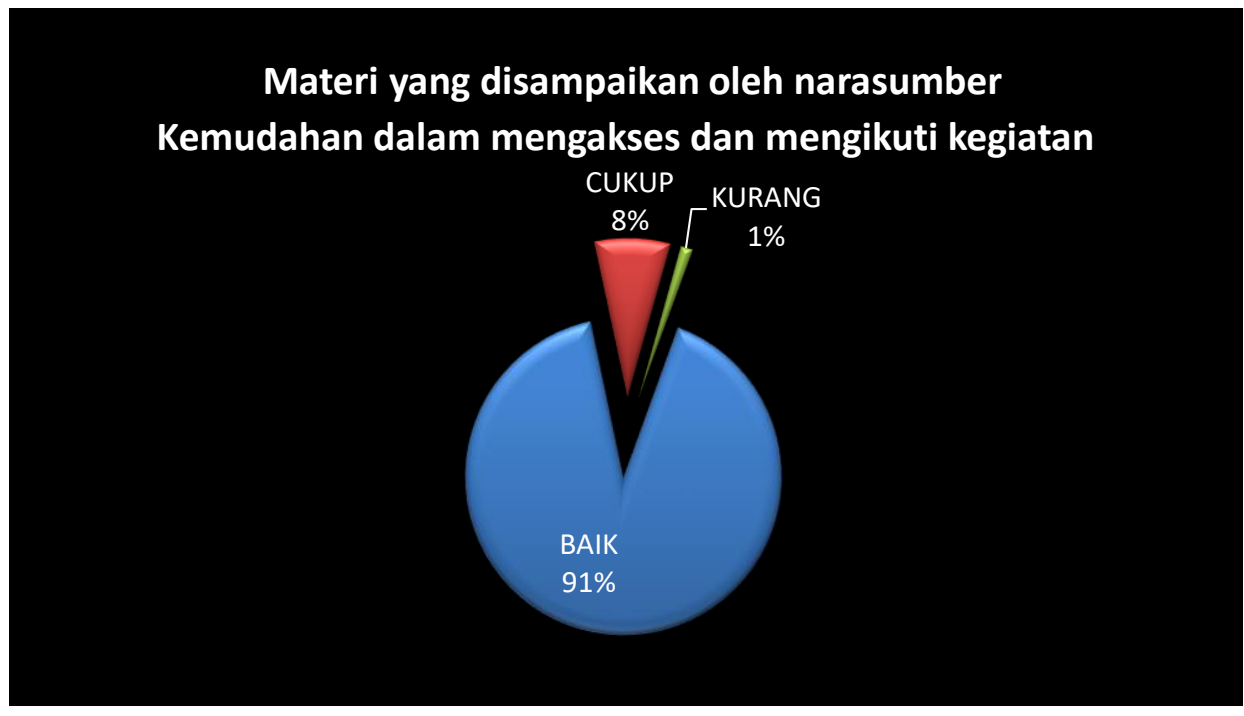

Gambar 6.2 . Hasil Evaluasi kegiatan webinar tentang Materi yang disampaikan oleh narasumber Kemudahan dalam mengakses dan mengikuti kegiatan (sumber : google Form webinar series 1, 2020)

3. Manfaat dari materi yang disampaikan dalam webinar ini bagi Anda Dari 158 peserta menyatakan bahwa Manfaat dari materi yang disampaikan dalam webinar ini bagi Anda yaitu Baik sebesar 143 orang (90\%), Cukup 14 Orang (9\%) dan 1 orang (1\%).dengan gambar grafik sebagai berikut :

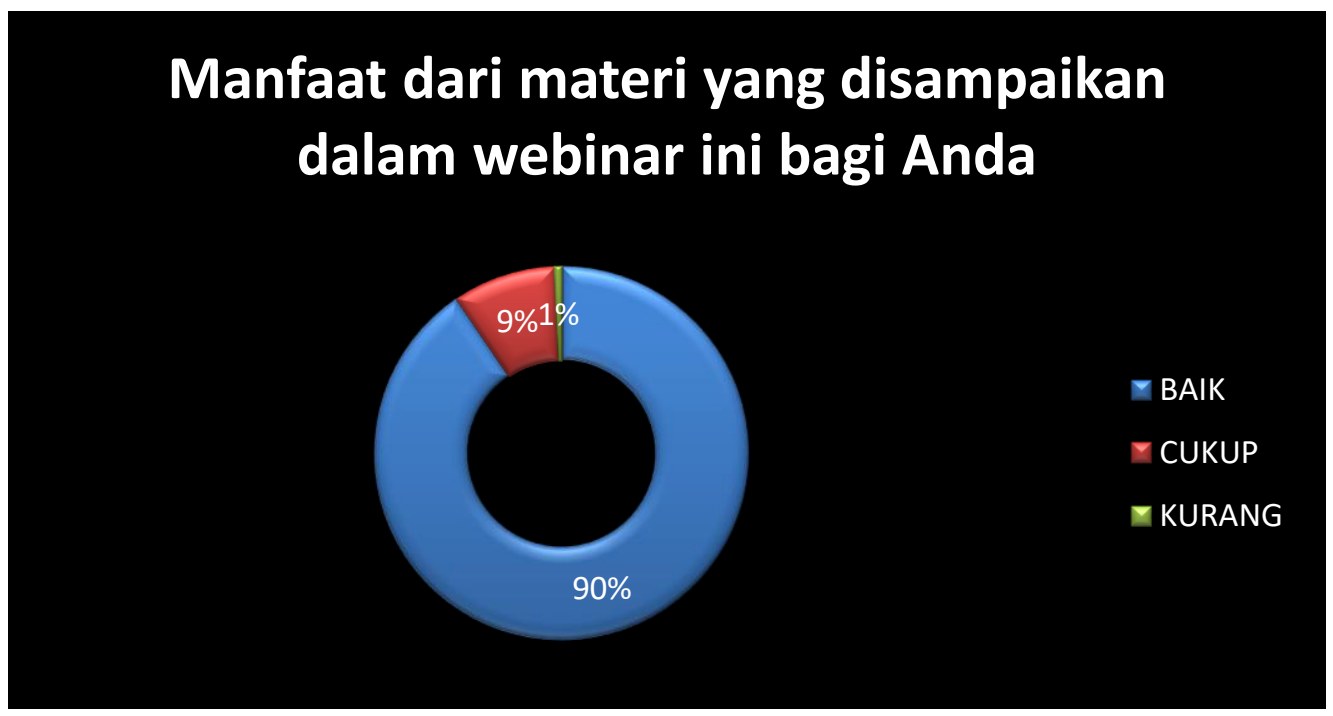


Gambar 6.3 . Hasil Evaluasi kegiatan webinar tentang Manfaat dari materi yang disampaikan dalam webinar ini bagi Anda

(sumber : google Form webinar series 1, 2020)

4. Kinerja Panitia

Dari 158 peserta menyatakan bahwa Manfaat dari materi yang disampaikan dalam webinar ini bagi Anda yaitu Baik sebesar 137 orang (87\%), Cukup 14 Orang (13\%) dan 1 orang (0 \%).dengan gambar grafik sebagai berikut :

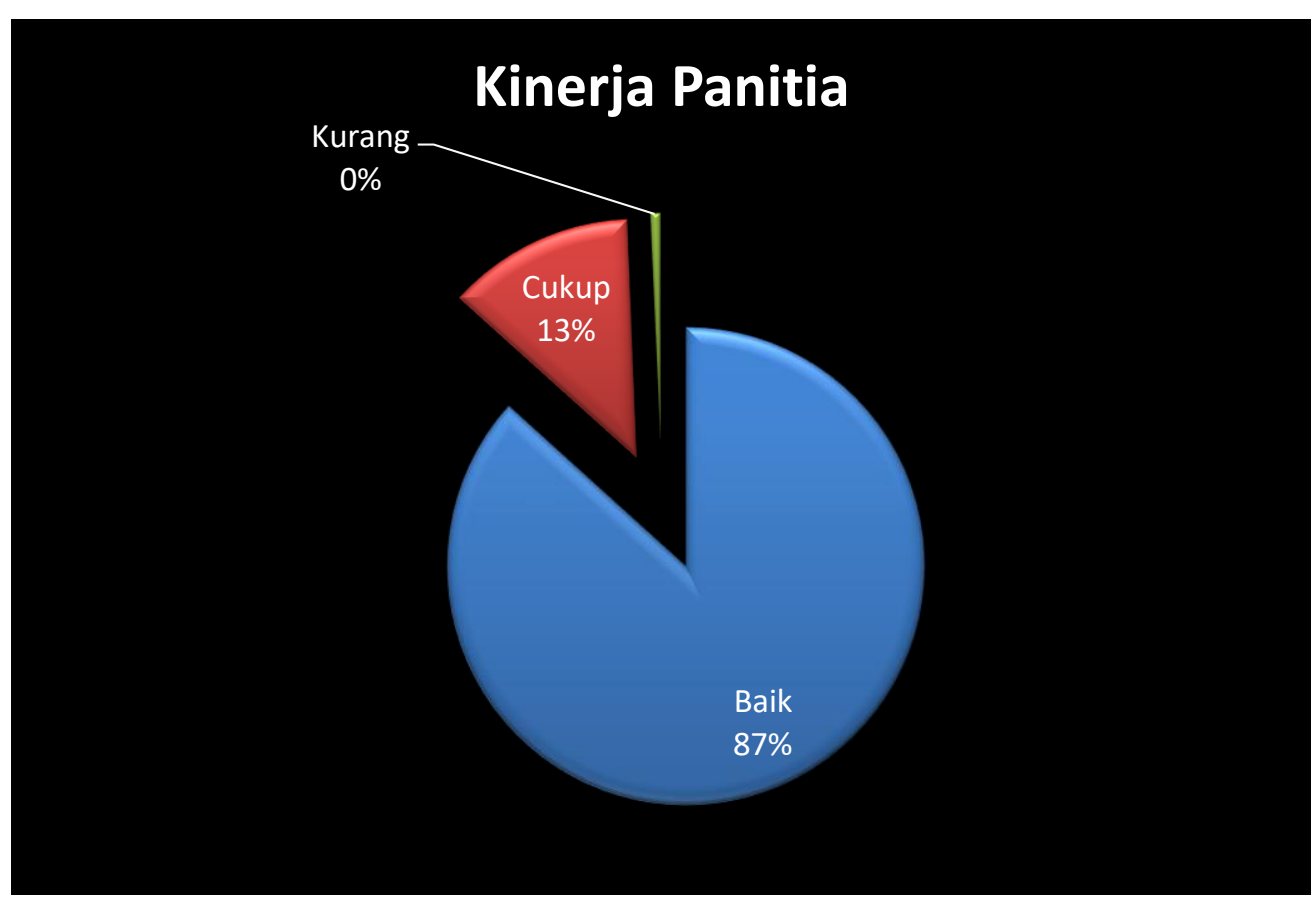

Gambar 6.4 . Hasil Evaluasi kegiatan webinar tentang Kinerja Panitia (sumber : google Form webinar series 1, 2020

\section{KESIMPULAN}

Pelaksanaan kegiatan PKM ini dapat berjalan dengan baik sebagai tombak pemberian informasi dan pengetahuan yang benar kepada masyarakat, terutama Keluarga Penderita DM, pemberian edukasi dari penyakit diabetes di Masyarakat dan peran keluarga pendamping DM sangat membentu masyarakat secara luas memahami informasi terkait Program Kemitraan Masyarakat Dalam Meningkatkan Peran Keluarga Dalam Pendampingan Trias Penatalaksanaan Penderita Diabetes Melitus Pada Lansia Di Kelurahan Cipayung Jakarta Timur yaitu dengan bekerjasama dengan pihak Puskesmas Kecamatan Cipayung sebagai pusat pelayanan yang berada di wilayah Cipayung jakarta timur dan dari evaluasis yang didapatkan dari Peserta 
sebagaian besar atau > 89 \% menyatakan program webinar ini baik dari segi kesiapan pendaftaran, pemateri, kemanfaatan bagi peserta dan Kinerja Panitia seminar.

\section{DAFTAR PUSTAKA}

Profil Puskesmas Cipayung Tahun 2017

Profil Kelurahan Cipayung Tahun 2018

BPJK Kesehatan Tahun 2014, Pengelolaan Penyakit Kronis, Cikarang, Cabang BPJS Kesehatan Badan Pusat Statistik Tahun 2014. Statistik Penduduk Lanjut Usia 2013. Hasil Survei Sosial Ekonomi Nasional. Jakarta: Badan Pusat Statistik.

Cramer, 1991, Compliance and Medical Practice Clinical Trial., http://www.pubmed.guv.

Vivien, Dwi, 2016, Pengetahuan dan Persepsi Prolanis dalam menjalani pengobatan di Puskesmas

Heny, Supduwinata, 2016, Usia Menopause Pada Wanita di Wilayah Kerja Puskesmas

Ezra, Ariestanti, Y, 2017, Faktor-faktor yang berhubungan dengan kepatuhan pasien diabetes mellitus dalam mengikuti kegiatan Prolanis 